\title{
Mechanical Model for Oblique Hole Drilling and Bit Life Analysis in Conventional Design
}

\author{
Weiyan $\mathrm{Xu}^{1, \mathrm{a}}$, Yanping Zhang ${ }^{2, \mathrm{~b}^{*}}$ and Juan Jiang ${ }^{1, \mathrm{c}}$ \\ ${ }^{1}$ Qingdao Binhai University, Qingdao,China \\ 2Qingdao University, Qingdao, China \\ a48875014@qq.com, b109976474@qq.com, c413544450@qq.com \\ * The corresponding author
}

Keywords: Bit; Oblique hole drilling; Mechanical model; ANSYS; Life estimation

\begin{abstract}
According to the practical condition and traditional design parameters of the oblique hole drilling, the mechanical model for the oblique hole drilling is established. With the finite element analysis software, two conditions are analyzed: the bit is not completely drilled into the workpiece, and the bit is completely drilled into the workpiece. At the same time, the effect of coaxiality error on the bit life is considered, and the influence law of the drill bush radial parameters on the bit life is analyzed. Then, the pre deformation method is adopted to solve the statically indeterminate problem by using the finite element software, and the comprehensive life analysis method for the bit life under multiple conditions is presented. Compared with the production in the enterprise, the theoretical analysis is consistent with the actual situation. The analysis shows that the feed rate of the oblique hole drilling and the coaxiality error are the key factors affecting the bit life.
\end{abstract}

\section{Introduction}

The drill bit is under the action of alternating stress at work, including the feeding force, cutting force, back force, the force of the inner wall of the drill bush, and the force of the inner wall of the hole, etc.. Because of the relatively poor working condition, and the shape constraints of the drill bit itself, the bit cuts at the single edge when working. The effect of the cutting force on the bit is to apply torque, the effect of the back force is to apply bending moment, and the feeding force acts along the axis of the drill bit. Moreover, due to the deformation of the bit, its contacts with the inner wall of the drill bush and the hole are point to point. So the point force acts on the bit. The space between the bit and the inner wall of the hole is about $0.01 \mathrm{~mm}$.

Although the bit is under unreasonable forces in the oblique hole drilling, the enterprise has to adopt the oblique hole drilling due to the structural limitations. The drill break occurs frequently. Fig. 1 illustrates a broke bit. Because of the unconventional cutting mode, the comprehensive analysis of the reasons for the bit break can not be presented easily. At the same time, because of the complex structure of the bit and the multiple forces on it, it is not easy to calculate the magnitude of the force, and it is difficult to build the mechanical model exactly. Because it belongs to high order statically determinate problem, the finite element software can not be used to solve it directly. A new calculation method needs designing. It is very difficult for the enterprise to improve the theoretical cutting parameters. Then lots of experiments have to be done. In order to reduce the cost, it is very necessary to identify the drilling process theoretically, and improve the processing parameters and the method rapidly and comprehensively. Therefore, it is of great theoretical significance and practical significance to establish the mechanical model of the oblique hole drilling and analyze the reasons for the bit break. 


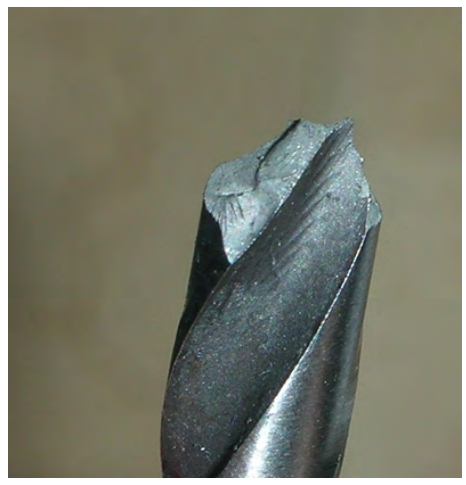

Figure 1. Finite The broken bit

The Analysis of the Forces and the Conditions in the Oblique Hole Drilling. The drill bush must be installed in the directly oblique hole drilling. In the working condition, the bit is under two forces which dynamically act. According to concrete operation, the drilling process is divided into two kinds of installation forms. One is the normal installation; the other is the abnormal installation. We define three conditions. The first one is that the bit is not completely drilled into the workpiece. The second is that the bit is completely drilled into the workpiece. The last is that the bit is just drilled out of the workpiece. In this paper, only the former two conditions are concerned. (Fig. 2 and Fig. 3 illustrate the two states).

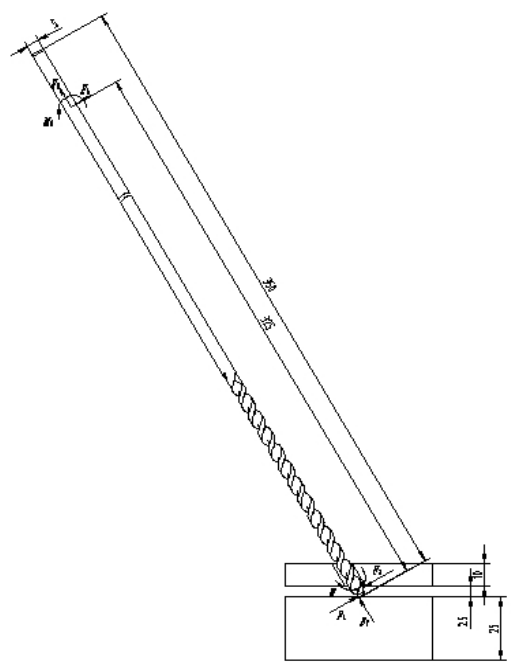

Figure 2. Finite The condition when the bit is not completely drilled into the workpiece

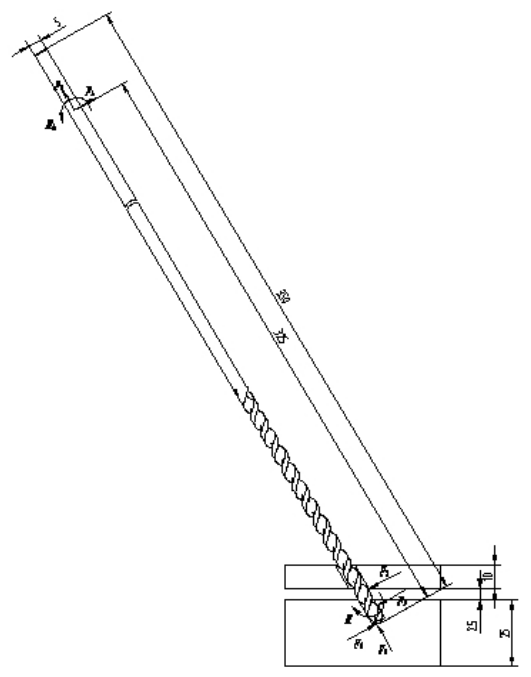

Figure 3. Finite The condition when the bit is completely drilled into the workpiece

The Selection of the Drilling Parameter and the Calculation of the Forces. In accordance with the national standard GB1438-78, high speed steel W6Mo5Gr4V2 is selected as the materials of the bit. The elastic modulus is $\mathrm{E}=216 \mathrm{GPa}$, Poisson's ratio is $\mu=0.13$, the ultimate strength is $\sigma_{b}=2100 \mathrm{MPa}$, the density of the material is 8110 . The actual data are used in analysis. The actual data are listed in Table 1. From calculation, we obtained the following data. The cutting feeding force is $\mathrm{Ff}=209 \mathrm{~N}$, the back force is $\mathrm{Fp}=54.6 \mathrm{~N}$, the cutting force is $\mathrm{Fc}=252.8 \mathrm{~N}$. With the cutting force we can get the cutting torque $\mathrm{Mc}=\mathrm{Fq} * \mathrm{r}$, where $\mathrm{r}$ is the radius of the bit. The data are listed in Table 2.

Table 1 The cutting parameters

\begin{tabular}{|c|c|c|c|c|c|}
\hline Parameters & Feed $(f)$ & $\begin{array}{c}\text { Linear velocity } \\
(\mathrm{Vc})\end{array}$ & Rotational speed $(\mathrm{n})$ & $\begin{array}{c}\text { Back cutting depth } \\
(\mathrm{ap})\end{array}$ & $\begin{array}{c}\text { Angle } \\
(\alpha)\end{array}$ \\
\hline Data & $0.07 \mathrm{~mm} / \mathrm{r}$ & $23.5 \mathrm{~m} / \mathrm{min}$ & $1500 \mathrm{r} / \mathrm{min}$ & $3 \mathrm{~mm}$ & 60 \\
\hline
\end{tabular}


Table 2 The structure parameters of the drilling mechanism

\begin{tabular}{|c|l|l|l|l|c|}
\hline Parameters & $\begin{array}{l}\text { Length of } \\
\text { the bit }\end{array}$ & $\begin{array}{l}\text { Diameter of } \\
\text { the bit }\end{array}$ & Depth & Inclined angle & $\begin{array}{c}\text { Distance between the drill bush } \\
\text { and the machining surface }\end{array}$ \\
\hline data & $350 \mathrm{~mm}$ & $5 \mathrm{~mm}$ & $25 \mathrm{~mm}$ & $60^{\circ}$ & $2.5 \mathrm{~mm}$ \\
\hline
\end{tabular}

The Simulation Analysis of the Drilling. The bit is a non-smooth cone, but it is constrained by a statistically determinate restraint in working. So it is a one order statically determinate structure. If the bit is completely into the hole, it is a two order statically determinate problem which is difficult to calculate by the traditional methods. Thus, the finite element software is adopted to calculate the forces on the bit, and the process is simulated with the traditional design data. In the analysis of the forces with the finite element software, fixed constraints are added at a distance of $25 \mathrm{~mm}$ from the top of the bit, coupled with the known force, and the statically determinate constraints. The size of its deformation is in tolerance zone, so that the static force is determined. The size of the drill bush is $\phi 5_{0+F 7}^{0+F 7}$, the size of the bit is $\phi 5_{-0.018}^{0}$. We consider the coaxality error of the drill bit and the drill bush to be a half of the tolerance, namely $0.009 \mathrm{~mm}$. Three conditions are considered. The first is that the bit is not completely into the workpiece. The second is the normal cutting when the bit is completely into the hole. The third is that the bit is through the workpiece. After considering the three effects and calculating the principal stress of the danger point, we compare the two individual stress and principal stress. It can be seen that the flexural bucking of the bit should be considered in simulation before checking. The stress in different conditions is shown in Fig. 4, Fig. 5, Fig. 6 and Fig. 7. We define the first working condition is that when the bit is not completely into the workpiece, and the second working condition is that when the bit is completely into the workpiece.

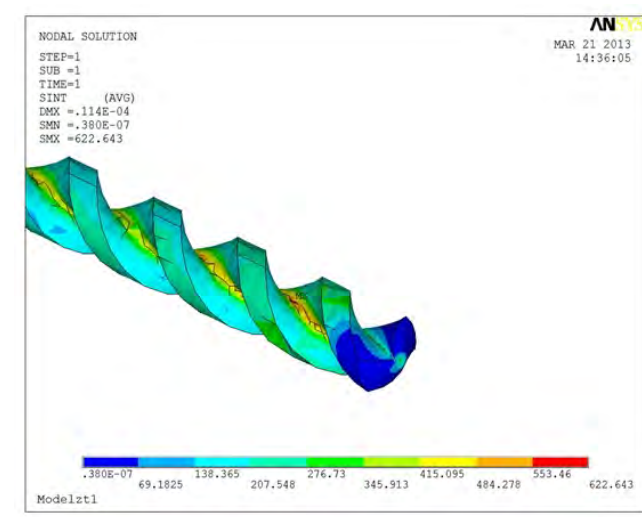

Figure 4. Finite Stress map without considering the co axiality error in the first condition

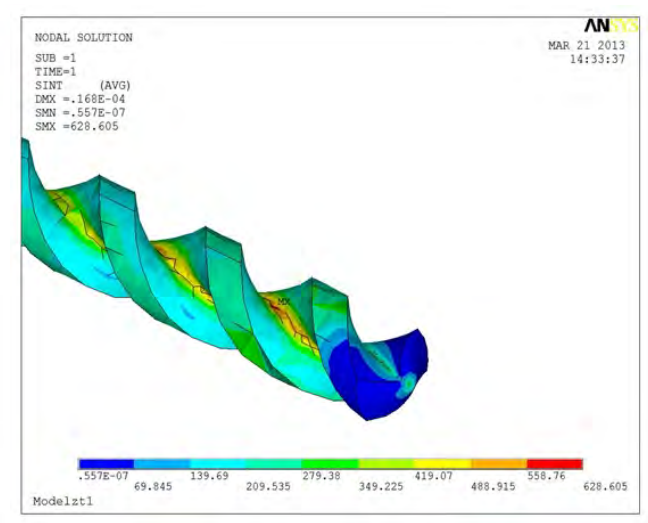

Figure 5. Finite Stress map considering the coaxiality error in the first condition 


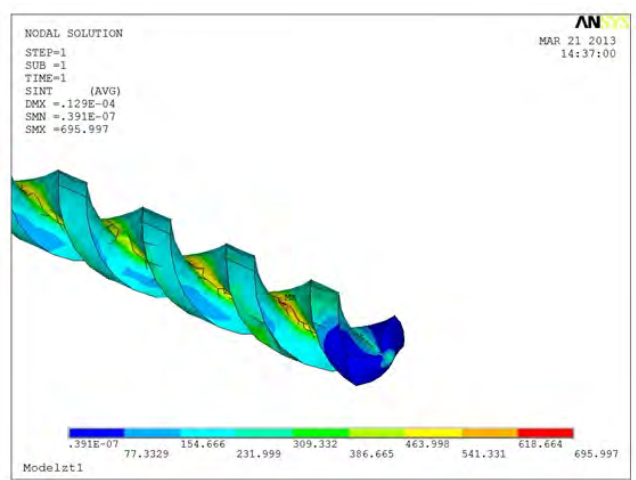

Figure 6. Finite Stress map without considering the coaxiality error in the serond condition

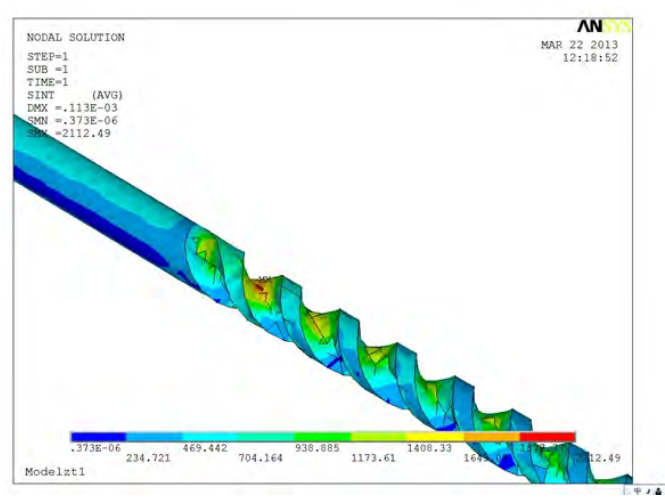

Figure 7. Finite Stress map without considering the coaxiality error and increasing the feed rate by a half in the second condition

When the bit is not completely into the workpiece and considering the coaxiality error, we select a unit in the positive direction of $\mathrm{Y}$ axis. The maximum stresses are as follows:

$\sigma_{x}=-403.69 \mathrm{MPa}, \sigma_{y}=-211.70 \mathrm{MPa}, \sigma_{z}=152.93 \mathrm{MPa}, \tau_{x y}=292.805 \mathrm{MPa}, \tau_{x z}=269.30 \mathrm{MPa}, \tau_{y z}=120.76 \mathrm{MPa}$

When the bit is not completely into the workpiece and considering the coaxiality error, we select a unit in the negative direction of $\mathrm{Y}$ axis. The maximum stresses are as follows:

$\sigma_{x}=261.99 \mathrm{MPa}, \sigma_{y}=143.93 \mathrm{MPa}, \sigma_{z}=-235.05 \mathrm{MPa}, \tau_{x y}=-273.53 \mathrm{MPa}, \tau_{z x}=-59.67 \mathrm{MPa}, \tau_{y z}=-117.93 \mathrm{MPa} .$.

When the bit is completely into the workpiece and not considering the coaxiality error, we select a unit in the positive direction of $\mathrm{Y}$ axis. The maximum stresses are as follows: $\sigma_{x}=-371.49 \mathrm{MPa}, \sigma_{y}=-205.06 \mathrm{MPa}, \sigma_{z}=147.17 \mathrm{MPa}, \tau_{x y}=-279.93 \mathrm{MPa}, \tau_{z x}=121.73 \mathrm{MPa}, \tau_{y z}=293.00 \mathrm{MPa}$.

When the bit is completely into the workpiece and not considering the coaxiality error, we select a unit in the negative direction of $\mathrm{Y}$ axis. The maximum stresses are as follows:

$\sigma_{x}=156.38 \mathrm{MPa}, \sigma_{y}=147.97 \mathrm{MPa}, \quad \sigma_{z}=-235.06 \mathrm{MPa}, \tau_{x y}=305.13 \mathrm{MPa}, \tau_{z x}=-112.37 \mathrm{MPa}, \tau_{y z}=-229.45 \mathrm{MPa}$.

\section{The Life Analysis}

The Calculation of the Maximum Principal Stress of the Workpiece. When the bit is not completely into the workpiece and not considering the coaxiality error, we consider the stress in the positive direction of Y axis.

The experienced formula of three dimensional stress state is presented as follows:

$$
\left|\begin{array}{ccc}
\sigma_{x}-\sigma & \tau_{y x} & \tau_{z x} \\
\tau_{x y} & \sigma_{y}-\sigma & \tau_{z y} \\
\tau_{x z} & \tau_{y z} & \sigma_{z}-\sigma
\end{array}\right|=0
$$

The above data are incorporated into formulation (1), then $\sigma_{1}$ and $\sigma_{3}$ can be calculated by matlab: $\sigma_{1}=364.17 \mathrm{MPa}, \sigma_{3}=-618.81 \mathrm{MPa}$.

To get the stress in the negative direction of $\mathrm{Y}$ axis without considering the coaxiality error when the bit is not completely drilled into the workpiece, the above data are incorporated into formulation (1), and the results are also can be got by Matlab : $\sigma_{1}=447.55 \mathrm{MPa}, \sigma_{3}=-767.13 \mathrm{MPa}$.

Similarly, we can get the stress in the positive direction of $\mathrm{Y}$ axis considering the coaxiality error when the bit is not completely drilled into the workpiece as follows: $\sigma_{1}=358.12 \mathrm{MPa}$, $\sigma_{3}=-646.86 \mathrm{MPa}$.

The stress in the negative direction of $\mathrm{Y}$ axis considering the coaxiality error when the bit is not 
completely drilled into the workpiece can be got as follows: $\sigma_{1}=314.75 \mathrm{MPa}, \sigma_{3}=-688.87 \mathrm{MPa}$.

The stress in the negative direction of $\mathrm{Y}$ axis without considering the coaxiality error when the bit is completely drilled into the workpiece as follows: $\sigma_{1}=533.97 \mathrm{MPa}, \sigma_{3}=-344.74 \mathrm{MPa}$.

The Calculation of the Life. The bit is under the action of alternating stress. There are interaction between the force in the positive direction of $\mathrm{Y}$ axis and the force in the negative direction of $\mathrm{Y}$ axis. In the selection of the maximum stress, to save a margin for the actual working state, we assume that the unit is under the maximum stresses both in the positive and negative direction of $\mathrm{Y}$ axis.

(1)The life calculation with the stress not considering the coaxiality error when the bit is not completely drilled into the workpiece.

In this condition, the maximum and the minimum stress are as follows:

$\sigma_{\text {max }}=364.17 M P a, \sigma_{\min }=-767.13 M P a$.

The ultimate strength of the material is: $\sigma_{\mathrm{b}}=2100 \mathrm{MPa}$.

The basic S-N curve is as follows: $S^{4} N=1.2 \times 10^{16}$.

The working cyclic stress amplitude can be calculated as follows: $\sigma_{a}=\left(\sigma_{\max }-\sigma_{\min }\right) / 2=565.65 \mathrm{MPa}$.

The average stress can be got: $\sigma_{m}=\left(\sigma_{\max }+\sigma_{\min }\right) / 2=-201.48 M P a$.

We know that: $\left(\sigma_{a} / \sigma_{a(R=-1)}\right)+\left(\sigma_{m} / \sigma_{b}\right)=1$

According the formulation (2), we can get $\sigma_{a(R=-1)}=516.13 \mathrm{MPa}$.

Then the life can be estimated as follows: $N=C / \sigma_{a(R=-1)}{ }^{m}=1.2 \times 10^{16} / 516.13^{4}=1.69 \times 10^{5}$ (次).

We assume that the thickness of the workpiece is $25 \mathrm{~mm}$, and the drill length is $5 \mathrm{~mm}$, then the number of the stress cycle needed by one hole can be calculated as follows: $z=30 / 0.07=428.6$.

The numbers of the workpieces machined by a bit under the normal condition can be got:

$$
n=\frac{N}{z}=\frac{1.69 \times 10^{5}}{428.6}=394 \text {. }
$$

(2)The life calculation with the stress considering the coaxiality error when the bit is not completely drilled into the workpiece

In this condition, the maximum and the minimum stress are as follows:

$\sigma_{\max }=509.10 \mathrm{MPa}, \sigma_{\min }=-646.86 \mathrm{MPa}$.

The ultimate strength of the material is: $\sigma_{\mathrm{b}}=2100 \mathrm{MPa}$,

The basic S-N curve is as follows: $S^{4} N=1.2 \times 10^{16}$.

The working cyclic stress amplitude can be calculated as follows: $\sigma_{a}=\left(\sigma_{\max }-\sigma_{\min }\right) / 2=577.98 \mathrm{MPa}$

The average stress can be got $\sigma_{m}=\left(\sigma_{\max }+\sigma_{\min }\right) / 2=-68.88 \mathrm{MPa}$

We know that $\left(\sigma_{a} / \sigma_{a(R=-1)}\right)+\left(\sigma_{m} / \sigma_{b}\right)=1$

According the formulation (2), we can get $\sigma_{a(R=-1)}=559.62 \mathrm{MPa}$.

Then the life can be estimated as follows: $N=C / \sigma_{a(R=-1)}{ }^{m}=1.2 \times 10^{16} / 559.62^{4}=1.22 \times 10^{5}$

We assume that the thickness of the workpiece is $25 \mathrm{~mm}$, and the drill length is $5 \mathrm{~mm}$, then the number of the stress cycle needed by one hole can be calculated as follows: $z=30 / 0.07=428.6$

The numbers of the workpieces machined by a bit under the normal condition can be got:

$$
n=\frac{N}{z}=\frac{1.22 \times 10^{5}}{559.62}=218
$$

(3)The life calculation with the stress not considering the coaxiality error when the bit is completely drilled into the workpiece.

In this condition, the maximum and the minimum stress are given as follows:

$\sigma_{\max }=533.97 \mathrm{MPa}, \sigma_{\min }=-688.87 \mathrm{MPa}$.

The ultimate strength of the material is: $\sigma_{\mathrm{b}}=2100 \mathrm{MPa}$,

The basic S-N curve is as follows: $S^{4} N=1.2 \times 10^{16}$. 
The working cyclic stress amplitude can be calculated as follows: $\sigma_{a}=\left(\sigma_{\max }-\sigma_{\min }\right) / 2=611.42 \mathrm{MPa}$.

The average stress can be got $\sigma_{m}=\left(\sigma_{\max }+\sigma_{\min }\right) / 2=-77.45 M P a$.

According the formulation (2), we can get $\sigma_{a(R=-1)}=589.67 \mathrm{MPa}$.

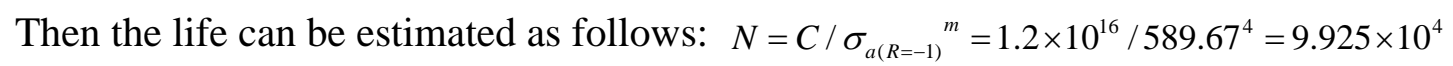

The numbers of the workpieces machined by a bit under the normal condition can be got:

$$
n=\frac{N}{z}=\frac{9.925 \times 10^{5}}{428.6}=231
$$

\section{The Life Analysis without Considering the Coaxiality Error and Increasing the Feed Rate by a Half when the Bit is Completely Drilled into the Workpiece.}

The stresses without considering the coaxiality error and increasing the feed rate by a half when the bit is completely drilled into the workpiece.Let consider the stresses without considering the coaxiality error when the feed rate is $0.01 \mathrm{~mm}$ and the bit is completely drilled into the workpiece.

A unit is selected in the positive direction of $\mathrm{Y}$ axis. We have calculated the maximum stresses as follows:

$\sigma_{x}=-1673.15 M P a, \sigma_{y}=-426.02 M P a, \sigma_{z}=311.07 M P a, \tau_{x y}=681.29 M P a, \tau_{z x}=846.16 M P a, \tau_{y z}=237.19 M P a$.

In the same condition, a unit is selected in the negative direction of $\mathrm{Y}$ axis. We have calculated the maximum stresses as follows:

$\sigma_{x}=1946.83 \mathrm{MPa}, \sigma_{y}=447.47 \mathrm{MPa}, \sigma_{z}=-329.45 \mathrm{MPa}, \tau_{x y}=-555.33 \mathrm{MPa}, \tau_{z x}=-401.35 \mathrm{MPa}, \tau_{y z}=-243.36 \mathrm{MPa}$.

The above data are incorporated into formulation (1), by matlab, we can get the stress in the positive direction of $\mathrm{Y}$ axis as follows: $\sigma_{1}=809.5 \mathrm{MPa}, \sigma_{3}=-2171.0 \mathrm{MPa}$.

The above maximum stresses are incorporated into formulation (1), by matlab, we can get the stress in the negative direction of $\mathrm{Y}$ axis as follows: $\sigma_{1}=2053.1 \mathrm{MPa}, \sigma_{3}=2.7 \mathrm{MPa}$.

The life calculation not considering the coaxiality error and increasing the feed rate by a half when the bit is completely drilled into the workpiece.In this condition, the maximum and the minimum stress are as follows:

$$
\sigma_{\text {max }}=2053.1 M P a, \sigma_{\min }=-2171.0 M P a \text {. }
$$

The ultimate strength of the material is: $\sigma_{\mathrm{b}}=2100 \mathrm{MPa}$.

The basic S-N curve is as follows: $S^{4} N=1.2 \times 10^{16}$.

The working cyclic stress amplitude can be calculated as follows:

$\sigma_{a}=\left(\sigma_{\max }-\sigma_{\min }\right) / 2=2112.05 \mathrm{MPa}$

The average stress can be got $\sigma_{m}=\left(\sigma_{\max }+\sigma_{\min }\right) / 2=8.95 \mathrm{MPa}$

We know that $\left(\sigma_{a} / \sigma_{a(R=-1)}\right)+\left(\sigma_{m} / \sigma_{b}\right)=1$

We can get $\sigma_{a(R=-1)}=2121.09 M P a$.

Then the life can be estimated as follows:

$$
N=C / \sigma_{a(R=-1)}^{m}=1.2 \times 10^{16} / 2121.09^{4}=592.85
$$

We assume that the thickness of the workpiece is $25 \mathrm{~mm}$, and the drill length is $5 \mathrm{~mm}$, then the number of the stress cycle needed by one hole can be calculated as follows: $z=30 / 0.07=428.6$

The numbers of the workpieces machined by a bit under the normal condition can be got:

$$
n=\frac{N}{z}=\frac{1.69 \times 10^{5}}{428.6}=1.4
$$

\section{Conclusion}

(1) A prediction method for the bit life in different conditions is presented. The specific conditions of the drill are considered. The prediction results are consistent with the actual results.

(2) The feed rate is the main factor affecting the life of drill bit, and it is also changeable factor leading to the changes of the actual work. 
(3) The effects of coaxiality on the bit life can not be ignored. In actual operations, in addition to improving the coaxiality accuracy, the installation of the bit should reach the installation requirements.

\section{References}

[1] P.L.Gui,M.G.Ji, Mechanical design, Beijing, (2006) 22-45.

[2] L.H.Wen, Mechanics of materials, Beijing, (2011) 343-365.

[3] G.S.Guang, ANSYS Engineering application example resolution, Beijing(2003)

[4] Z.Y.Hang,H.Guo,Q.He,X.J.Yang, Research on the drilling process based on finite element method, Journal of natural sciences (2012) 87-112.

[5] C.C.Zhou,P.Chi,T.Dong, The finite element analysis of the drill force based on ALGOR, Mechanical research and application (2012)

[6] L.Chao, Static analysis and research of bit dynamic based on finite element method, Huazhong university of science and technology (2009)

[7] K.Lan,Q.L.Chen, Finite element analysis of gasoline drilling bit based on ANSYS, Tool technology (2008)

[8] J.J.Tong,D.M.Sun,Y.P.Hu, Analysis on the stiffness of ANSYS - shaped twist drill, Mechanical design and manufacturing (2007)

[9] N.M.Zhi,J.J.Yi,Y.He, Finite element analysis of solid carbide twist drill, carbide (2007)

[10]W.Lei,G.C.Wang, Research progress in finite element simulation of drilling process, Tool technology (2007)

[11]KHARKEVICH A.VENUVINOD P K, Basic geometric analysis of 3-D chip forms in metal cutting.Partl:determining uprcurl and side-curl radii, International Journal of Machine Tools and Manufacturem, (1999) 751-769.

[12]JSStrenkowski, CCHsieh, AJShih, An analytical finite element technique for predicting thrust force and torque in drilling, InternationalJournal ofMachine Tools\&Manufacture (2004) 